\title{
EDUCAÇÃO ESPECIAL E INCLUSÃO: O QUE DIZEM OS PROFESSORES NOS PRIMEIROS ANOS DE CARREIRA DOCENTE NA REDE PÚBLICA MUNICIPAL DE ENSINO EM MACEIÓ-AL?
}

\author{
SPECIAL EDUCATION AND INCLUSION: WHAT DO TECHERS SAY \\ IN THE FIRST YEARS OF A TEACHING CAREER IN THE \\ MUNICIPAL PUBLIC NETWORK OF EDUCATION IN MACEIÓ-AL?
}

\author{
D Eva Pauliana da Silva Gomes \\ Doutoranda em Educação \\ Universidade Federal de Alagoas - UFAL. \\ Maceió, Alagoas - Brasil. \\ e.pauliana@gmail.com \\ Edna Cristina do Prado \\ Doutorado em Educação \\ Universidade Federal de Alagoas - UFAL. \\ Maceió, Alagoas - Brasil. \\ wiledna@uol.com.br
}

Resumo: O objetivo central da presente pesquisa é apresentar a promoção, os obstáculos e as perspectivas da inclusão escolar no Ensino Fundamental I a partir da percepção dos professores que estão no início da carreira docente na rede pública de ensino municipal da capital alagoana. A pesquisa tem uma abordagem qualitativa e utilizaram-se questionários. Os resultados apontam que os professores com carreira docente iniciante veem a inclusão escolar com avanços adquiridos a partir de aspectos legais, mas afirmam que a implementação na prática ainda é distante da realidade. A promoção explicita-se na garantia da acessibilidade ao cotidiano escolar. Entre os obstáculos, destacamse as limitações da formação inicial; a ausência de apoio pedagógico e a adaptação de atividades a partir das necessidades educacionais das crianças e as perspectivas estão relacionadas à constante busca por verdadeiros espaços de aprendizagem inclusiva com práticas pedagógicas que atendam às especificidades de cada criança.

Palavras-chave: educação especial; inclusão escolar; carreira docente inicial.

Abstract: The main objective of the present research is to show the promotion, the obstacles and the perspectives of the school inclusion in Elementary School I from the perception of the teachers who are in the beginning of the teaching career in the public system of municipal education of the capital of Alagoas. The research has a qualitative approach and questionnaires were used. The results show that teachers with a beginning teaching career see school inclusion with advances acquired from legal aspects, but claim that implementation in practice is still far from reality. The promotion is explicit in guaranteeing accessibility to school daily life. Among the obstacles are the limitations of initial training; the absence of pedagogical support and the adaptation of activities based on the educational needs of children and the perspectives are related to the constant search for true spaces of inclusive learning with pedagogical practices that meet the specificities of each child.

Keywords: special education; school inclusion; early teaching career.

\section{Para citar-ABNT NBR 6023:2018}

GOMES, Eva Pauliana da Silva; PRADO, Edna Cristina do. Educação especial e inclusão: o que dizem os professores nos primeiros anos de carreira docente na rede pública municipal de ensino em Maceió-AL? Cadernos de Pós-graduação, São Paulo, v. 20, n. 1, p. 128-144, jan./jun. 2021. Disponível em: https://doi.org/10.5585/cpg.v20n1.19176. 


\section{Introdução}

No contexto educacional brasileiro, há várias maneiras de propor a garantia, o acesso e a permanência dos alunos da educação especial no âmbito escolar. Neste sentido, o olhar direcionase aos aspectos legais, ao trabalho em equipe, à formação continuada dos professores, às adaptações curriculares e aos aspectos organizacionais da gestão escolar, pois tornam-se estratégias valorizadas e imprescindíveis para atender às várias necessidades de todos os estudantes.

Entretanto, mesmo com os aspectos organizacionais e os avanços, inúmeros obstáculos são encontrados, pois “[...] as barreiras à aprendizagem e à participação dificultam o cotidiano escolar dos alunos em situação de inclusão, sendo necessária a mobilização de recursos - humanos, físicos, políticos etc. - nas escolas e comunidades" (OLIVA, 2016, p. 492). Neste aspecto, tendo em vista o aprendizado na sala de aula, o papel dos professores torna-se fundamental para promover o planejamento curricular, a interação, a cooperação e a avaliação.

Considerando as várias demandas à prática pedagógica no âmbito escolar, bem como as lacunas, fragilidades e dificuldades encontradas nos primeiros anos da docência, este artigo tem como objetivo apresentar a promoção, os obstáculos e as perspectivas da educação inclusiva no Ensino Fundamental I a partir da percepção dos professores que estão no início da carreira docente na rede pública de ensino municipal da capital alagoana. Assim, foi realizada uma pesquisa de abordagem qualitativa, com a aplicação de questionário com 4 (quatro) professores efetivos com carreira inicial no ensino público da rede municipal de ensino em Maceió. O critério de escolha dos sujeitos da pesquisa deu-se pela aprovação no último concurso para professor efetivo na rede municipal da capital alagoana, realizado no ano de 2017, além disso, foi considerado o nível acadêmico, ou seja, dos 190 (cento e noventa) aprovados, escolheu-se os com maior titulação. Os sujeitos escolhidos possuem, pelo menos, uma especialização, mestrado em educação e, atualmente, são doutorandos, também em educação na Universidade Federal de Alagoas.

As categorias de análise - formação inicial e formação continuada - foram definidas a priori à luz da Análise de Conteúdo, visto ser um conjunto de técnicas de “[...] análise das comunicações visando obter, por procedimentos, sistemáticos e objetivos de descrição do conteúdo das mensagens, indicadores que permitam a inferência de conhecimentos relativos às condições de produção destas mensagens" (BARDIN, 2002, p. 4).

Quanto à estrutura, o presente artigo apresenta duas seções, além da introdução e das considerações finais. A segunda seção, intitulada como "Educação Especial e Inclusão: bases legais no contexto político brasileiro", enfatiza um olhar para o processo histórico da legislação, apresentando os avanços alcançados a partir da década de 1990 no Brasil, enquanto a terceira, denominada “A visão dos professores iniciantes sobre inclusão escolar: promoção, obstáculos e perspectivas na 
prática pedagógica", analisa os discursos sobre o ensino inclusivo das crianças com necessidades educativas especiais no Ensino Fundamental I com o intuito de mostrar a realidade do cotidiano escolar maceioense.

\section{Educação especial e inclusão: bases legais no contexto político brasileiro}

Nas últimas décadas no Brasil, os temas concernentes à Educação Especial, às práticas com as crianças e às alternativas de formação continuada têm ganhado destaque nas discussões, na política e no marco legal. "A evolução e democratização da sociedade modificaram os conceitos de educação especial, enquanto área isolada no contexto escolar, e exigiram uma proposta de educação inclusiva" (SILUK, 2014, p. 28).

A discussão sobre a política de educação especial na perspectiva da educação inclusiva constitui uma trajetória entre interesses e forças políticas, econômicas e sociais. O acesso, a permanência e a boa qualidade fazem parte do processo de lutas e as políticas públicas destacam-se nesse processo de buscas de resultados.

No contexto das políticas públicas, a educação inclusiva é um direito de todos os alunos e requer mudanças nos aspectos organizacionais da escola, do currículo, da avaliação da aprendizagem, da gestão da escola, da sala de aula e da formação continuada dos professores. A igualdade de condições para o acesso e a permanência na escola passou a ter garantia após a promulgação da Constituição Federal (CF) de 1988. O Artigo 208 apresenta, como dever do Estado, a oferta do atendimento educacional especializado, preferencialmente na rede regular de ensino (BRASIL, 1988).

A partir de 1990, o marco de debates sobre a Educação Inclusiva foi constituído com a Declaração Mundial sobre Educação para todos, a qual apresenta um Plano de Ação para satisfazer as necessidades básicas de aprendizagem, aprovado na Conferência Mundial em Jomtien. Além dele, destaca-se a Declaração de Salamanca (1994), que apresenta princípios, política e práticas na área das necessidades educativas especiais e assegura que " $[. .$.$] as escolas devem acolher a todas as$ crianças, independentemente de suas condições físicas, intelectuais, sociais, emocionais, linguísticas ou outras" (UNESCO, 1994, p.17).

Em âmbito nacional, a Lei de Diretrizes e Bases da Educação Nacional (LDBEN no 9.394/96) define a educação especial como uma modalidade a ser ofertada preferencialmente na rede regular de ensino e o seu Artigo 59 assinala que os sistemas de ensino assegurarão currículos, métodos, técnicas, recursos educativos e organização específicos para atender às necessidades (BRASIL, 1996). 
GOMES, Eva Pauliana da Silva; PRADO, Edna Cristina do. Educação especial e inclusão: o que dizem os professores nos primeiros anos de carreira docente na rede pública municipal de ensino em Maceió-AL

Os avanços na legislação foram sendo destaque como mostra o decreto $\mathrm{n}^{\circ} 3.076$, de 01 de junho de 1999, o qual cria o Conselho Nacional dos Direitos da Pessoa Portadora ${ }^{1}$ de Deficiência (CONAE). Após dois anos, foi definida a Lei no 10.172/2001, que sancionou a implantação do Plano Nacional de Educação (PNE), sendo que a educação especial neste documento aparece em destaque com 28 (vinte e oito) metas, entre elas, salientam-se o interesse na implantação de programas, melhorias na infraestrutura das escolas e o desafio de garantir, em cinco anos, o ensino da Língua Brasileira de Sinais (LIBRAS). O PNE (2001-2010) reforça a responsabilidade do governo federal, estados e municípios com a educação especial, mesmo após o término de sua vigência, poucas foram conquistas para a área em tela, poucas ações deram concretude ao disposto no texto e muitos foram os entraves.

Para o fortalecimento da organização no ensino especial, a Resolução do Conselho Nacional de Educação e da Câmara de Educação Básica de 2001 (Resolução CNE/CEB nº 2/2001) institui as Diretrizes Nacionais para a Educação Especial na Educação Básica, em todas as etapas e modalidades, o documento faz referência à integração social das pessoas com necessidades educacionais especiais, bem como evidencia a importância de práticas heterogêneas e inclusivas.

Tendo em vista a importância da integração social, o reconhecimento da LIBRAS como meio de comunicação e expressão deu-se com a Lei n ${ }^{\circ}$ 10.436/2002 e, após três anos, o decreto $n^{\circ}$ 5.625/2005 incluiu a LIBRAS como disciplina curricular obrigatória nos cursos de formação de professores com o intuito de avalizar o desenvolvimento da linguagem na educação dos surdos.

Em 2007, a garantia de acesso, participação e aprendizagem dos alunos com deficiência, transtornos globais do desenvolvimento e altas habilidades/superdotação nas escolas regulares foi consolidado com a implementação da Política de Educação Especial na Perspectiva da Educação Inclusiva (PNEEPI), a qual constitui um paradigma educacional fundamentado na concepção de direitos humanos, na indissociabilidade entre igualdade/diferença e na superação da exclusão dentro e fora da escola (GARCIA; MICHELS, 2011).

$\mathrm{Na}$ especificidade da educação básica, as políticas públicas viabilizam um planejamento financeiro, curricular e organizacional das instituições de ensino. O Atendimento Educacional Especializado (AEE) é uma das propostas de política pública que visa garantir a educação para todos. Neste sentido, o CNE instituiu a resolução n ${ }^{\circ} 4$ (quatro), de 02 de outubro de 2009, a qual apresenta as Diretrizes Operacionais para o AEE na Educação Básica, o documento menciona, no Artigo 2, que o AEE tem como função complementar ou suplementar a formação do aluno por meio da

\footnotetext{
${ }^{1}$ Ao longo da história, vários termos foram criados, tais como: anormais, idiotas, incapacitados, excepcionais, deficientes e, mais atualmente, pessoas portadoras de deficiência, pessoas com deficiência, pessoas portadoras de necessidades especiais e pessoas com necessidades educacionais especiais (SILVA, 2010, p. 80).
} 
disponibilização de serviços, recursos de acessibilidade e estratégias que eliminem as barreiras para a sua plena participação na sociedade e o desenvolvimento de sua aprendizagem.

Nessa perspectiva de garantia e organização sobre o marco legal do AEE, o Artigo 10, inciso I das Diretrizes Operacionais, enfatiza que o projeto pedagógico da escola é um dos mecanismos de conduta que deverá institucionalizar [...] sala de recursos multifuncionais: espaço físico, mobiliário, materiais didáticos, recursos pedagógicos e de acessibilidade e equipamentos específicos (BRASIL, 2009).

O Decreto 7.611, de 17 de novembro de 2011, traz os objetivos do AEE.

Art. $3^{\circ}$ São objetivos do atendimento educacional especializado: I - prover condições de acesso, participação e aprendizagem no ensino regular e garantir serviços de apoio especializados de acordo com as necessidades individuais dos estudantes;

II - garantir a transversalidade das ações da educação especial no ensino regular;

III - fomentar o desenvolvimento de recursos didáticos e pedagógicos que eliminem as barreiras no processo de ensino e aprendizagem; e IV - assegurar condições para a continuidade de estudos nos demais níveis, etapas e modalidades de ensino (BRASIL, 2011, p. 02).

O marco legal apresenta que o AEE é parte integrante do processo educacional, o qual é realizado na sala de recursos multifuncionais no âmbito escolar que o aluno frequenta ou em outra instituição. Entre as ações do apoio técnico e financeiro, o Art $5^{\circ}$, inciso IV, considera relevante a formação de gestores, educadores e demais profissionais da escola para a educação na perspectiva da educação inclusiva, particularmente na aprendizagem, na participação e na criação de vínculos interpessoais (BRASIL, 2011). Para uma melhor compreensão das ações que devem ser estabelecidas a partir do planejamento da política pública, o quadro abaixo expressa os tipos de atividades do AEE. 
GOMES, Eva Pauliana da Silva; PRADO, Edna Cristina do. Educação especial e inclusão: o que dizem os professores nos primeiros anos de carreira docente na rede pública municipal de ensino em Maceió-AL

Quadro 01 - Atividades do Atendimento Educacional Especializado (AEE)

\begin{tabular}{ll}
\hline $\mathbf{1}$ & Ensino do Sistema de Braille \\
\hline $\mathbf{2}$ & Ensino do Uso de Recursos Ópticos e não Ópticos \\
$\mathbf{3}$ & Estratégias para o desenvolvimento de Processos Mentais \\
$\mathbf{4}$ & Técnicas de Orientação e Mobilidade \\
$\mathbf{5}$ & Ensino da Língua Brasileira de Sinais (LIBRAS) \\
$\mathbf{6}$ & Ensino do Uso da Comunicação Alternativa e Aumentativa \\
& (CAA) \\
$\mathbf{7}$ & Estratégias para Enriquecimento Curricular \\
$\mathbf{8}$ & Ensino das Técnicas de Soroban \\
& Ensino da Usabilidade e das Funcionalidades da Informá- \\
$\mathbf{1 0}$ & tica Acessível \\
$\mathbf{1 1}$ & Ensino da Língua Portuguesa na Modalidade Escrita \\
\hline
\end{tabular}

Fonte: INEP/Censo Escolar, 2018.

O quadro 01 traz a lista de atividades que devem ser realizadas com os alunos deficientes, as quais buscam promover a aprendizagem a partir dos recursos didáticos e pedagógicos disponibilizados na escola pública em consonância ao disposto na meta 4 (quatro) do atual PNE (20142024), instituído por meio da Lei no 13.005/2014, que estabelece o acesso à Educação Básica e ao atendimento educacional especializado para toda a população de 4 (quatro) a 17 anos com deficiência, transtornos globais do desenvolvimento e altas habilidades ou superdotação. Observa-se que já se passaram seis anos de implementação do PNE e ainda não há uma política de monitoramento e avaliação da referida meta para mencionar como tem se dado a acessibilidade dos alunos. Assim, "[...] é preciso investigar, de uma maneira criteriosa, a forma como tem ocorrido a materialização dessas políticas públicas nas estruturas municipais para melhor entender seu impacto na garantia ao direito à educação do PAEE”. (BARBOSA; FUMES 2018, p. 285). Neste sentido, a próxima seção traz uma apresentação da rede pública municipal de Maceió e a análise das falas dos docentes com carreira iniciante no processo de inclusão escolar das crianças com necessidades educacionais especiais na rede pública municipal de Maceió. 


\section{Metodologia}

A metodologia da presente pesquisa esteve pautada na abordagem qualitativa. "A pesquisa qualitativa responde a questões muito particulares. Ela se preocupa, nas ciências sociais, com o nível de realidade que não pode ser quantificado. Ou seja, ela trabalha com o universo de significados [...]" (MINAYO, 2002, p. 21). A coleta de dados deu-se no Centro de Educação da Universidade Federal de Alagoas, especificamente no Programa de Pós-Graduação em Educação (PPGE). A análise dos dados foi realizada a partir da Análise de Conteúdo (BARDIN, 2002) das categorias - formação inicial e formação continuada.

Localizada na região Nordeste do país, a cidade de Maceió possui $509,320 \mathrm{~km}^{2}$ e o total de 1.018.948 habitantes, segundo os dados do Instituto Brasileiro de Geografia e Estatística (IBGE, 2019). A cidade tem duzentos e cinco anos e é representada por um patrimônio natural, histórico e cultural com uma riqueza deslumbrante, "[...] Maceió é uma das mais belas capitais brasileiras, conhecida como o "paraíso das águas", um dos destinos mais procurados pelo turismo nacional. É

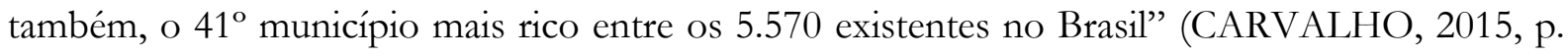
104). Contraditoriamente, também se destaca por seus problemas, tais como: falta de saneamento básico, violência e taxa de analfabetismo.

Ao direcionar o olhar para a estrutura organizacional, os dados do Censo Escolar (2018) mostram que o número de escolas na rede pública maceioense é de 140 (cento e quarenta), sendo 93 (noventa e três) do Ensino Fundamental, 47 (quarenta e sete) da Educação Infantil com o total de 3.579 (três mil, quinhentos e setenta e nove) docentes, destes, 3.462 (três mil, quatrocentos e sessenta e dois) atuando em sala de aula e 117 (cento e dezessete) com atuação no Atendimento Educacional Especializado (AEE).

Ao observar os dados do censo escolar de 2018, há uma discrepância no número de escolas, pois a capital maceioense possui 140 (cento e quarenta) escolas e o número total de salas de recursos multifuncionais é de 78 (setenta e oito). Dessa forma, são 62 (sessenta e duas) escolas sem a consolidação da política pública do AEE, o que chama atenção é que a política foi institucionalizada em 2008 e, durante uma década, considerando os dados de 2018, o número de escolas que garante o plano de atendimento individual com atividades complementares frente ao discurso de garantia e permanência está longe de ser consolidado. Ainda segundo o censo, o quadro abaixo apresenta o número de matrículas no Ensino Regular e na Educação Especial nas redes estadual, municipal e privada no município. 
GOMES, Eva Pauliana da Silva; PRADO, Edna Cristina do. Educação especial e inclusão: o que dizem os professores nos primeiros anos de carreira docente na rede pública municipal de ensino em Maceió-AL

Quadro 02 - Número de Matrículas - AL - Total por Município - Censo Escolar 2018

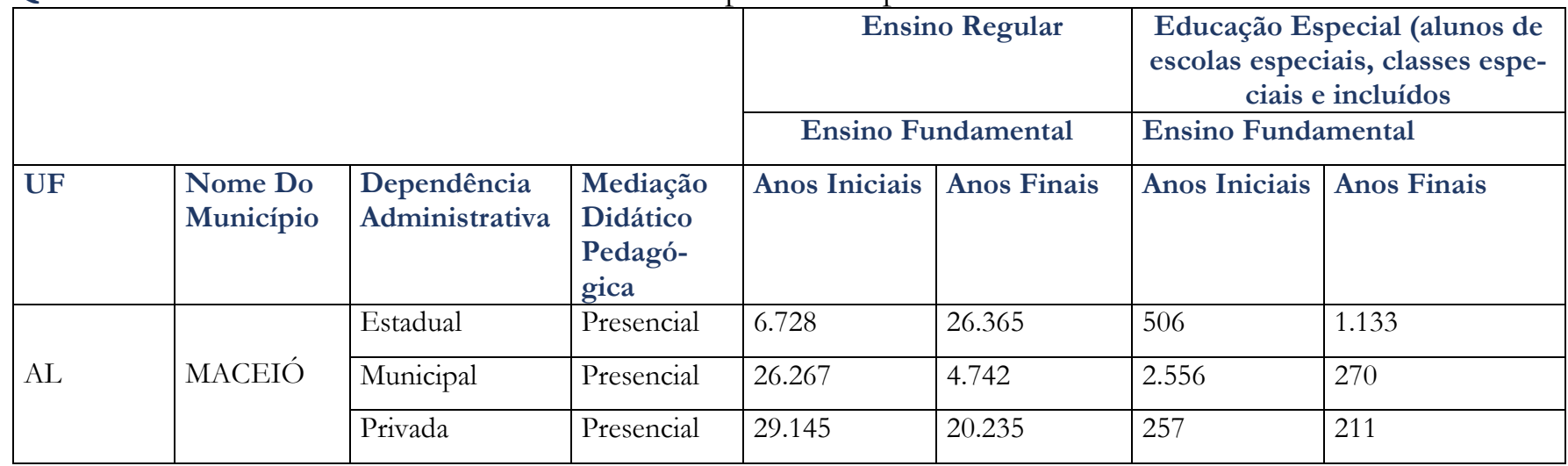

Fonte: Deed/INEP/MEC.

O quadro 02 deixa explícito o número de matrículas na capital alagoana. Na Educação Especial, percebe-se que os Anos Iniciais mostram-se com maior representatividade e o número mais elevado dessas matrículas está na rede municipal de ensino, com um total de 2.556 (dois mil, quinhentos e cinquenta e seis) crianças matriculadas nessa modalidade de ensino para 117 (cento e dezessete) professores atuando no AEE, se dividirmos, tem-se uma média de 22 alunos com necessidades especiais por docente. Já nos anos finais, o número de matrículas é bem mais baixo, destacando só 270 (duzentos e setenta), sendo assim, pode-se refletir sobre a fragilidade do acesso e permanência dos jovens na escola.

Diante de tal realidade, algumas inquietações surgem "Como tem sido o início da carreira docente frente ao número elevado de matrículas na educação especial? Os docentes com carreira inicial sentem-se preparados nas ações pedagógicas a partir das necessidades educacionais especiais dos alunos??. A partir das indagações, a literatura afirma que o início da carreira docente é marcado por "[...] tensões e de intensas aprendizagens que contribuem, de maneira essencial, para a construção da identidade docente e a estruturação da prática profissional” (LEONE; LEITE; 2011, p. 240).

Partindo desse pressuposto, os sujeitos da pesquisa foram 4 (quatro) professores com carreira docente iniciante, sendo 3 (três) professoras e 1 (um) professor, todos eles com formação em Pedagogia, especialização lato sensu, mestrado em Educação e doutorandos em Educação na Universidade Federal de Alagoas (UFAL), os quais fazem parte do quadro de profissionais efetivos da Secretaria Municipal de Educação (SEMED) em Maceió e atuam no Ensino Fundamental I, conforme o quadro abaixo. 
GOMES, Eva Pauliana da Silva; PRADO, Edna Cristina do. Educação especial e inclusão: o que dizem os professores nos primeiros anos de carreira docente na rede pública municipal de ensino em Maceió-AL

Quadro 03 - Perfil dos sujeitos da pesquisa

\begin{tabular}{|c|l|l|l|l|}
\hline Professor & Idade & \multicolumn{1}{|c|}{ Formação } & $\begin{array}{l}\text { Tempo de Carreira } \\
\text { Docente/Carga } \\
\text { Horária de Traba- } \\
\text { lho }\end{array}$ & $\begin{array}{c}\text { Turma } \\
\text { em que } \\
\text { leciona }\end{array}$ \\
\hline P1 & 33 & $\begin{array}{l}\text { Pedagogia, Especialização em Alfabetização e } \\
\text { Letramento, mestrado e doutoranda em Educa- } \\
\text { ção. }\end{array}$ & $\begin{array}{l}2 \text { anos e oito } \\
\text { meses / 25 h }\end{array}$ & $2^{\circ}$ Ano \\
\hline P2 & 35 & $\begin{array}{l}\text { Pedagogia, Especialização em Educação } \\
\text { Infantil, Mestrado e Doutoranda em Educação. }\end{array}$ & $\begin{array}{l}3 \text { anos e cinco me- } \\
\text { ses/ }\end{array}$ & $1^{\circ}$ Ano \\
\hline P3 & 31 & $\begin{array}{l}\text { Pedagogia, Especialização em Direitos } \\
\text { Humanos, Mestrado e Doutoranda em } \\
\text { Educação. }\end{array}$ & $\begin{array}{l}2 \text { anos e três meses/ } \\
25 \mathrm{~h}\end{array}$ & $3^{\circ}$ Ano \\
\hline P4 & 32 & $\begin{array}{l}\text { Pedagogia, Especialização em Gestão } \\
\text { Educacional, Mestrado e Doutorando em Edu- } \\
\text { cação. }\end{array}$ & $\begin{array}{l}1 \text { ano e cinco meses/ } \\
25 \mathrm{~h}\end{array}$ & $1^{\circ}$ Ano \\
\hline
\end{tabular}

Fonte: Dados da Pesquisa, 2020.

O quadro anterior traz o perfil dos sujeitos da pesquisa, a faixa etária está entre 31 e 35 anos e o tempo de carreira docente está entre 1 (um) e 3 (três) anos e cinco meses, atuando nas turmas de $1^{\circ}$ ao $3^{\circ}$ Ano do Ensino Fundamental I com carga horária semanal de 25 horas. O trabalho destina-se a 17 horas em sala de aula, 3 (três) horas de planejamento e 5 horas de formação continuada.

4 A visão dos professores iniciantes sobre inclusão escolar: promoção, obstáculos e perspectivas na prática pedagógica em Maceió-AL

No contexto das políticas educacionais, a formação inicial e continuada dos professores torna-se um dos principais meios para favorecer a permanência e sucesso dos alunos na escola, assim o "[...] especial destaque cabe aos profissionais da educação - principais agentes do processo de escolarização - que, atuando diretamente junto aos alunos, desempenham papel determinante para a qualidade da educação" (PEREIRA; TEIXEIRA, 2015, p. 183).

$\mathrm{Na}$ sala de aula, os sujeitos da pesquisa afirmaram que trabalham ou já trabalharam com crianças com deficiência, muitas sem laudos médicos e, entre aquelas com laudos, destacam-se as do Transtorno do Espectro Autismo (TEA), Transtorno do Déficit de Atenção e Hiperatividade (TDAH) ou Surdez. 
GOMES, Eva Pauliana da Silva; PRADO, Edna Cristina do. Educação especial e inclusão: o que dizem os professores nos primeiros anos de carreira docente na rede pública municipal de ensino em Maceió-AL

Quadro 04 - Número de alunos na sala de aula

\begin{tabular}{|l|l|l|l|l|}
\hline Professor & \multirow{2}{*}{$\begin{array}{c}\text { Turma em } \\
\text { que leciona }\end{array}$} & \multirow{2}{*}{$\begin{array}{c}\text { Número to- } \\
\text { tal de alu- } \\
\text { nos }\end{array}$} & \multicolumn{2}{|c|}{$\begin{array}{c}\text { Alunos com necessida- } \\
\text { des especiais }\end{array}$} \\
\cline { 4 - 6 } & & c/laudo & s/ laudo \\
\hline P1 & $2^{\circ}$ Ano & 25 & 2 & 1 \\
\hline P2 & $1^{\text {o Ano }}$ & 20 & 1 & 2 \\
\hline P3 & $3^{\text {o Ano }}$ & 25 & 1 & 3 \\
\hline P4 & $1^{\circ}$ Ano & 20 & 1 & 1 \\
\hline
\end{tabular}

Fonte: Dados da Pesquisa, 2020.

O quadro mostra o número de alunos, as turmas de $1^{\circ}$ Ano possuem 20 (vinte) alunos ao total, a turma do P3 e do P4 têm crianças com surdez, ambas têm laudo. As crianças fazem acompanhamento duas vezes por semana na Associação de Pais e Amigos dos Excepcionais (APAE) e têm atendimento complementar na sala de recursos multifuncionais em outra instituição de ensino da rede municipal, pois as escolas não possuem o atendimento educacional especializado. Já o P1 atua numa turma de $2^{\circ}$ Ano, as crianças com laudo apresentam Transtorno do Espectro Autismo (TEA) e Transtorno do Déficit de Atenção e Hiperatividade (TDAH). O P2 afirmou que a criança com laudo tem TEA.

Tendo em vista o foco da presente pesquisa, indagou-se aos sujeitos "o que significa a inclusão escolar de alunos com deficiência na escola?”

Vejo a questão da inclusão como um direito conquistado e muito necessário para que a educação seja para todos. [...] Para mim, incluir é atender essas crianças, jovens ou adultos com dignidade, com profissionais preparados e estrutura necessária. A inclusão não é tratar de uma forma especial, mas reconhecer que todos nós temos limitações e que elas devem ser consideradas em todas as suas dimensões, para que assim, garanta a socialização e o desenvolvimento pleno dos sujeitos com necessidades especiais. (P1, grifo nosso).

Significa a oportunidade de proporcionar maior interação entre a criança com necessidades especiais e as demais, bem como, ampliar o convívio social destes. A legislação deixa claro como esse atendimento nas escolas deve ocorrer diante da obrigatoriedade da matrícula desses alunos em salas regulares, porém, a escola, especialmente, a pública não possui o preparo e a estrutura necessária, apesar dos investimentos governamentais nessa modalidade educacional. (P2, grifo nosso).

Significa a oportunidade de maior interação, mas a realidade nos mostra a necessidade de professores capacitados que atendam estas crianças no cotidiano escolar. (P3, grifo nosso).

No sentido ético-político representa um avanço [...] No entanto, no sentido de efetivação das políticas educacionais, a sua implementação está distante da realidade da escola pública. No entanto, no sentido de efetivação das políticas educacionais, a sua implementação está distante da realidade da escola pública [...] faz-se necessário um investimento pessoal e financeiro para concretização da política. Percebe-se uma ausência de formação de professores e de pessoas capacitadas para lidar com a realidade existente. (P4, grifo nosso). 
As falas apresentadas reconhecem a educação inclusiva das crianças com deficiência como direito conquistado na legislação, garantindo a efetivação da matrícula, bem como a socialização, porém chamam atenção quando afirmam que inclusão vai além desses aspectos organizacionais, pois a estrutura física, o planejamento pedagógico e outras ações práticas precisam ser revistas. De acordo com Silva (2010, p. 100) a inclusão escolar “[...] trata-se de um processo que exige o questionamento e revisão de posturas e práticas que há muito tempo vinham sendo desenvolvidas no ambiente escolar".

Percebe-se, nas falas, a preocupação e a crítica dos profissionais sobre a política de formação de professores, pois os profissionais sentem-se inseguros na prática com as deficiências que as crianças apresentam. Diante disso, pode-se indagar "Dilema? Desafio? Contraposição ao sistema? Sim, mas muito mais, compromisso com a oferta de uma educação com qualidade, que necessita contar com pessoal formado adequadamente" (BRZEZINSKI, 2014, p. 120).

Os sujeitos da pesquisa alegaram que já tiveram ou têm alunos com deficiência assíduos, mas, a partir da vivência no chão da escola pública, destacaram que, desde que ingressaram até o momento da presente pesquisa, não houve, por parte da SEMED/Maceió, proposta de formação sobre educação especial. Segundo dados da SEMED/Maceió, a rede tem, desde 2014, uma parceria com o Projeto das Nações Unidas para o Desenvolvimento (PNUD), entre as ações, destaca-se uma perspectiva participativa e de integração com o intuito de inovar e consolidar premissas educacionais, entre elas, uma estratégia de formação continuada de professores, mas não há nenhuma referência acerca da formação docente na área da educação especial.

Os sujeitos da pesquisa foram indagados se, no início da carreira docente, eles enfrentam ou já enfrentaram algum obstáculo para incluir o aluno com deficiência, todos afirmaram que:

\footnotetext{
Nos dois anos que atuo como docente, deparei-me com 4 casos de crianças com necessidades de atendimento educacional especializado com laudo. Dos quatro confirmados, somente 1 obteve o direito de ser acompanhado por uma auxiliar porque conquistou esse direito na justiça. Os obstáculos que posso listar relacionam-se com o apoio de um/a auxiliar e a adaptação de atividades [...]. O maior desafio é a adaptação das atividades para essas crianças e a atenção, pois um professor com 25 alunos em sala não tem como oferecer um atendimento especial a essas crianças e deixar os demais desassistidos. (P1, grifo nosso).
}

Já tive alunos com necessidades especiais em sala, confesso que foi muito difícil de lidar com essas crianças por não ter apoio e nem preparação para atender suas necessidades, a escola não tinha sala de recursos multifuncionais e isso dificulta bastante o trabalho no dia a dia na escola (P2, grifo nosso). 


\begin{abstract}
Na minha turma tenho um aluno surdo [...] De início ele estava sendo acompanhado pela estagiária da SEMED, estudante do curso de Pedagogia, nesta etapa que ela esteve presente mostrou que não conhecia a LIBRAS, não foi fácil, pois os gestos que ela fazia era apenas "não" e "sim". [...] após dois meses de aula, a estagiária foi indicada para outra escola e a intérprete de Libras iniciou o seu trabalho na sala de aula, a prática pedagógica tornou-se integrada, pois diante da experiência que ela possui, a mesma ajuda no planejamento das atividades bem como na socialização da criança com a LIBRAS.(P3, grifo nosso).
\end{abstract}

Tenho uma aluna surda e a minha maior dificuldade é desenvolver atividades para que ela possa desenvolver juntamente com os demais colegas, uma vez que não tenho uma formação específica e ainda não foi possível contar com o apoio de um(a) intérprete de libras. A aluna surda necessita de atividades voltadas para a sua compreensão, que aborda a Língua Brasileira de Sinais (LIBRAS), mas as limitações na formação inicial, a falta de apoio pedagógico, de um auxiliar de sala ou intérprete de libras dificulta o planejamento destas atividades (P4, grifo nosso).

Em todas as manifestações, é possível identificar que os professores enfrentam obstáculos. A P1 afirma que a adaptação de atividades, a ausência de auxiliar e o número de alunos na sala de aula são apresentados como alguns fatores que impedem a concretude do ensino inclusivo. Stainback e Stainback (1999) mostram que há componentes práticos interdependentes necessários para a garantia de um ensino inclusivo, os quais são caracterizados a partir do componente organizacional, do trabalho em equipe e da aprendizagem cooperativa, tornando-se relevante destacar que, a partir dos discursos analisados até aqui, esses componentes não foram mencionados pelos sujeitos da pesquisa.

Já a fala da P2 enfatiza a importância da sala de recursos multifuncionais referindo-se ao AEE, “[...] esse atendimento, segundo o prescrito no conjunto de normas legais, objetiva contribuir na escolarização do PAEE, sendo preconizado que esteja integrado à proposta pedagógica da escola” (BARBOSA; FUMES 2018, p. 283). Os conteúdos pedagógicos do AEE (LIBRAS, Braille, Tadoma, Sorobã, Tadoma, Comunicação Aumentativa e Alternativa) visam à eliminação das barreiras, considerando as especificidades das crianças. Mercado (2016), em sua tese de doutorado, mostra a importância do AEE realizado nas Salas de Recursos Multifuncionais (SRM) em Maceió e afirma que a precarização do ensino e a má qualidade da formação não é superada com a implantação de SRM. Diante da realidade da educação na capital alagoana, exposta nas falas aqui analisadas e nos estudos de Fumes, Barbosa (2018) e Mercado (2016), pode-se ponderar que os programas não têm sido suficientes para o alcance de melhorias no trabalho escolar.

As narrativas dos professores 3 (três) e 4 (quatro) demonstram os obstáculos no processo de ensino e aprendizagem com a educação dos surdos no momento de incluí-los no ambiente de aprendizagem. Diante disso, Quadros (1997, p. 28) afirma que “[...] a criança surda irá integrar-se satisfatoriamente à comunidade ouvinte somente se tiver uma identificação bastante sólida com o grupo, caso contrário terá dificuldades". A partir dos relatos, percebe-se que os entraves estão associados à realidade psicossocial, cultural e linguística da criança surda. As experiências naturais 
com a LIBRAS tornam-se imprescindíveis e podem efetivar ações práticas diferentes, no entanto, a escola precisa apresentar uma proposta educacional que "[...] além de ser bilíngüe, deve ser bicultural para permitir o acesso rápido e natural da criança surda à comunidade ouvinte e para fazer com que ela se reconheça como parte de uma comunidade surda” (Ibid, p. 28).

Apesar dos obstáculos listados, evidencia-se o quanto a inclusão escolar pode ser benéfica às crianças matriculadas na rede municipal de ensino, mas os benefícios poderiam ser mais eficazes a partir da garantia da acessibilidade, participação e permanência no âmbito escolar, conforme preconizado na legislação nacional. Os docentes apresentam minimamente os benefícios da inclusão escolar.

[...] o mais importante é fazer com que aquela criança se socialize e se desenvolva de maneira sadia e plena. (P1, grifo nosso).

[...] interação das crianças, ajudando bastante no processo de socialização (P2, grifo nosso).

[...] socialização, participação dos pais, tendo em vista que ficam mais à vontade e motivados no acompanhamento da vida escolar do filho(a). (P3, grifo nosso).

[...] possibilidade de o aluno ocupar um espaço que já era seu de direito, tornando-se, assim, um cidadão ativo na sociedade. (P4, grifo nosso).

Os termos sublinhados "socialização e participação" remetem ao espaço de acolhimento com o intuito de evitar a segregação e o isolamento do PAEE sem qualquer tipo de preconceito, principalmente na sala de aula. Dessa forma, percebe-se que a Educação Especial de Maceió tem conseguido algo benéfico, sim - a socialização -, mas a garantia da aprendizagem é mais visível nos aspectos legais do que na implementação das políticas nos espaços escolares, assim o direito constitucional não tem sido efetivado. As crianças "ocupam espaço", "socializam", os "pais participam", mas continuam sem aprender.

A partir do benefício mais elencado sobre o olhar da inclusão escolar - socialização -, os participantes destacaram as mudanças que foram alcançadas na prática pedagógica.

Busquei aprofundar minhas leituras com relação à educação especial, além de buscar desenvolver estratégias para que esses alunos fossem atendidos com dignidade, mesmo em meio à falta de estrutura e pessoal da escola em que atuo. (P1, grifo nosso).

Mudou muita coisa, os planos de aula são mais flexíveis, aprendi a lidar melhor com as diferenças no cotidiano. Rever minha atuação profissional. (P2, grifo nosso).

Percebo que houve um avanço significativo com a presença da intérprete de Libras na sala de aula, pois há um diálogo na organização do planejamento e nas atividades garantindo a participação e aprendizagem da criança. (P3, grifo nosso). 
[...] uma maior cobrança na direção/coordenação de um Intérprete de Libras, momentos de discussão com a turma sobre a importância da inclusão. Acredito que o diálogo é fundamental para que as práticas de discriminação no cotidiano sejam abolidas e o respeito e a interação prevaleça na sala de aula tornando um espaço de aprendizagem para todos (P4, grifo nosso, grifo nosso).

Ao analisar as falas anteriores, compreende-se que a prática pedagógica dos profissionais está direcionada por uma abordagem mais diversificada, flexível e colaborativa. Os relatos enfatizam que os planejamentos das ações práticas passaram por adaptações curriculares e os planos de aula destacam-se como instrumento principal para flexibilizar atividades para as crianças reforçando a autonomia. Sendo assim, isso inclui uma demonstração de iniciativa com o intuito de alcançar o fornecimento de assistência necessária, apesar de que a luta não pode ser limitada na busca da autonomia, ela é necessária, porém a tônica da escola tem que ser o aprendizado dos alunos e a formação continuada é o foco principal no processo de reflexão e/ou socialização das práticas vivenciadas pelo professor, o qual poderá avaliar e perceber as mudanças que podem ser realizadas na organização do ato de planejar.

Percebe-se que o diálogo é visto como primordial para mediar as relações interpessoais, além disso, o papel dos gestores é essencial na busca por mudanças, pois "[..] os gestores devem mediar as inter-relações e interações para que ocorra um processo de ensino-aprendizagem inclusivo e qualitativo, de forma que estejam sempre atentos à legislação e às políticas públicas vigentes" (AZEVEDO; CUNHA, 2008, p. 66). Logo, a equipe gestora precisa articular o processo da educação inclusiva e oportunizar a integração entre todos os envolvidos.

Em relação às perspectivas, espera-se o desenvolvimento de estratégias, as quais podem estar vinculadas a projetos na perspectiva da interdisciplinaridade e transdisciplinaridade, buscando a garantia da aprendizagem dos alunos com diferentes tipos de deficiência seja auditiva, múltipla, física, intelectual, altas habilidades/superdotação, cegueira, baixa visão, Síndrome de Rett, Síndrome de Asperger, Síndrome de Down, entre outras. Além disso, espera-se pelo ingresso de novos docentes por meio de aprovação em concurso público e por uma política de formação continuada aos docentes de toda a rede municipal com o olhar específico para a educação especial, propondo, a cada mês, sugestões de plano de ação com atividades integradoras, dinâmicas e lúdicas.

\section{Considerações Finais}

O paradigma da Política Nacional da Educação Especial na Perspectiva Inclusiva na sociedade brasileira é fundamentado no planejamento da garantia dos direitos humanos e na indissociabilidade entre igualdade e diferença. Desse modo, o processo histórico dentro desse contexto mostra as lutas, os entraves e os avanços conquistados a partir dos aspectos legais, mas “[...] é válido mencionar que os princípios legais não garantem a almejada educação socialmente referenciada 
explícita nos documentos, pois os desafios perpassam a gestão e a formação dos profissionais da educação" (BRZEZINSKI, 2014, p. 114).

Ao concordar com as afirmações de Brzezinski (2014) sobre o distanciamento entre a legislação e a efetividade das práticas nas escolas, o presente artigo buscou mostrar a promoção, os obstáculos e as perspectivas da inclusão escolar no ensino fundamental I a partir da percepção dos professores que estão no início da carreira docente na rede pública de ensino municipal da capital alagoana. Diante das categorias - formação inicial e formação continuada -, o olhar foi direcionado para análise dos questionários respondidos por 4 (quatro) professores efetivos da secretaria municipal de educação de Maceió.

A análise dos dados mostrou que os professores com carreira docente iniciante veem a inclusão escolar com avanços adquiridos a partir de aspectos legais, mas afirmam que a implementação, na prática, torna-se distante da realidade, pois são vários os desafios no processo de ensino e aprendizagem. Para uma melhor compreensão da vivência desses desafios, eles foram pontuados como obstáculos, os quais se destacam nas limitações da formação inicial e continuada, ausência de apoio pedagógico e adaptação de atividades a partir das deficiências das crianças. A promoção está explícita na garantia da acessibilidade ao cotidiano escolar, a qual se resume na interação, participação e respeito, mas o componente principal, que é a aprendizagem, precisa de um olhar mais significativo, pois o aluno com deficiência necessita da assistência técnica especializada para o seu desenvolvimento integral, conforme está posto nas políticas de educação especial.

As perspectivas estão relacionadas à busca de um espaço de aprendizagem inclusivo com práticas pedagógicas que atendam às especificidades de cada criança, assim é almejada a realização de concursos públicos; estratégias didático-pedagógicas; projetos apresentando ações inter e transdisciplinares e implementação de salas de recursos multifuncionais em todas as escolas da rede para diminuir as barreiras urbanísticas, atitudinais e tecnológicas.

Torna-se importante mencionar que, mesmo apresentando a promoção, os obstáculos, e as perspectivas dos docentes no início da carreira, a presente pesquisa não conseguiu apresentar todas as demandas relacionadas ao início da carreira e à educação especial. Mesmo assim, espera-se que tenha contribuído para despertar o interesse sobre a temática e suscitar outras investigações sobre ensino público da capital alagoana.

Portanto, a pesquisa trouxe alguns aspectos da realidade enfrentada no dia a dia nas instituições de ensino em Maceió e deixou explícita a fragilidade na efetivação da meta 4 do PNE, o qual garante o atendimento educacional especializado aos alunos com deficiência, bem como a implementação das salas de recursos multifuncionais propostas na política pública do AEE. 
GOMES, Eva Pauliana da Silva; PRADO, Edna Cristina do. Educação especial e inclusão: o que dizem os professores nos primeiros anos de carreira docente na rede pública municipal de ensino em Maceió-AL

\section{Referências}

AZEVEDO, Maria Antonia Ramos de; CUNHA, Gracilliani Rosa da. Gestão Escolar e Educação Inclusiva: uma parceria necessária e emergente na escola. Educação: Teoria e Prática - v. 18, n.31, jul.-dez.2008, p.53-72. Rio Claro, SP, Brasil - eISSN: 1981-8106.

BARDIN, Laurence. Análise de conteúdo. Trad. Luís Antero Reto e Augusto Pinheiro. Lisboa: Edições 70, 2002.

BARBOSA, Marily Oliveira Barbosa. FUMES, Neiza de Lourdes Frederico. Educação Especial no município de Maceió/ Alagoas: a fragilidade das políticas públicas. Cad. Cedes, Campinas, v. 38, n. 106, p. 281-298, set.-dez.., 2018.

BRASIL. Decreto n 3.076, de 01 de junho de 1999. Disponível em: <http:/ /www.planalto.gov.br/ccivil_03/decreto/d3076.htm>. Acesso em: 14 jan de 2021.

BRASIL. Decreto $n^{0} 5.625$, de 22 de dezembro de 2005. Disponível em: <http://portal.mec.gov.br/index.php?option $=$ com_docman\&view $=$ download\&alias $=9961$-decreto-5626-2005-secadi\&Itemid=30192>. Acesso em: 10 jan. 2021.

BRASIL. Lei no 13.005, de 25 de junho de 2014. Disponível em: < https://www2.camara.leg.br/legin/fed/lei/2014/lei-13005-25-junho-2014-778970-publicacaooriginal-144468-pl.html. Acesso em: 02 jan. 2021.

BRASIL. Lei n 10.172, de 9 de janeiro de 2001. Disponível em: <http:/ /www.planalto.gov.br/ccivil_03/leis/leis_2001/110172.htm>. Acesso em: 02 dez. 2020.

BRASIL. Decreto n 7.611, de 17 de novembro de 2011. Disponível em: <http:/ /www.planalto.gov.br/ccivil_03/_ato2011-2014/2011/decreto/d7611.htm>. Acesso em 04 dez. 2020.

BRZEZINSKI, Iria. Formação de profissionais da Educação e mudanças da LDB/1996: dilemas e desafios? Contradições e compromissos? BRZEZINSKI, Iria (Org.) LDB/1996 Contemporânea: contradições, tensões, compromissos. São Paulo, Cortez, 2014.

CARVALHO, Cícero Péricles. A Economia. MENDONÇA, Carlos Alberto; AMORIM, Luis (Orgs.). Maceió Duzentos Anos. Instituto Arnon de Mello, 2015.

GARCIA, Rosalba Maria C.; MICHELS, Maria Helena. A política de educação especial no Brasil (19912011): uma análise da produção do GT 15 - Educação Especial da Anped. Rev. Bras. Ed. Esp., Marília, v.17, p.105-124, Maio-Ago., 2011. Edição Especial.

LEONE, Naiara Mendonça; LEITE, Yoshie Ussami Ferrari. O início da carreira docente: implicações à formação inicial de professores. Revista Eletrônica Pesquiseduca - p.236- 259 - v. 03, n. 06 - jul. -dez. 2011.

OLIVA, Diana Villac. Barreiras e recursos à aprendizagem e à participação de alunos em situação de inclusão. Psicol. USP vol.27 no.3 São Paulo set./dez. 2016. Disponível em:

< https://www.scielo.br/pdf/pusp/v27n3/1678-5177-pusp-27-03-00492.pdf>. Acesso em: 14 jan 2021. 
PEREIRA, Eva Waisros. ZULEIDE, Araújo. Reexaminado a educação básica na LDB: ganhos e perdas após dezessete anos. BRZEZINSKI, Iria (Org.). LDB/1996 Contemporânea: contradições, tensões e compromissos.

QUADROS, Ronice Muller de. Educação de surdos a aquisição da linguagem. Porto Alegre: Editora Artes Médicas Sul Ltda, 1997.

SILVA, Aline Maria. Educação Especial e Inclusão Escolar. Curitiba: Ibpex, 2010.

SILUK, Ana Cláudia Pavão (Org.). Atendimento Educacional Especializado: contribuições para a prática pedagógica. 1.ed., 1. reimpr. Santa Maria: Laboratório de pesquisa e documentação-ce. Universidade Federal de Santa Maria: ufsm, 2014

STAINBACK, S. et al. A aprendizagem nas escolas inclusivas: e o currículo?. In: STAINBACK, S. \& STAINBACK, W. Inclusão: Um guia para educadores. Tradução de Magda França Lopes. Porto Alegre: Artmed Editora S.A., 1999. pg. 240 - 250. 